\title{
Poorly Formed Pattern
}

National Cancer Institute

\section{Source}

National Cancer Institute. Poorly Formed Pattern. NCI Thesaurus. Code C113734.

A morphologic finding indicating the presence of a malignant cellular infiltrate with poorly defined glands in a tissue sample. 